\title{
Oleanolic acid enhances the radiosensitivity of tumor cells under mimetic hypoxia through the reduction in intracellular GSH content and HIF-1 $\alpha$ expression
}

\author{
RONGXIN QI, WENWEN JIN, JUAN WANG, QIYI YI, MAOHU YU, SHIGUO XU and WENSEN JIN \\ Teaching and Research Section of Nuclear Medicine, Anhui Medical University, Hefei, Anhui 230032, P.R. China
}

Received December 24, 2013; Accepted February 21, 2014

DOI: $10.3892 / o r .2014 .3064$

\begin{abstract}
We previously found that oleanolic acid (OA), a naturally pentacyclic triterpenoid, enhances the radiosensitizing effect on tumor cells. However, it is unclear whether or not OA enhances the radiosensitivity of hypoxic cells. Therefore, the aim of the present study was to further observe the influence of OA on hypoxic tumor cells, and the relative mechanism was also investigated. The radiosensitivity of rat glioma C6 cells and human lung cancer A549 cells with different treatments, under mimetic hypoxia, was evaluated by clonogenic assay. A micronucleus (MN) test, meanwhile, was utilized to observe the alteration in intracellular DNA damage. For determining the mechanism involved in the OA influence on the radiosensitivity of hypoxic cells, we determined the levels of intracellular reduced glutathione (GSH) using the glutathione reductase/5,5'-dithiobis-(2-nitrobenzoic acid) (DTNB) recycling assay. Simultaneously, the activities of $\gamma$-glutamylcysteine synthetase $(\gamma$-GCS) and GSH synthase (GSS), both enzymes for GSH synthesis, were tested using appropriate methods. Due to the involvement of hypoxia inducible factor- $1 \alpha$ (HIF-1 $\alpha)$ in the resistence of hypoxic cells to radiation damage, its levels were also observed by western blot method. The results from this study demonstrated that the clonogenic growth of irradiated cells was increased under mimetic hypoxia while the refractory effect of hypoxic cells to radiation was decreased following OA treatment. Moreover, the $(\mathrm{MN})$ frequencies in the hypoxic cells treated with $\mathrm{OA}$ were augmented after irradiation compared with the cells without OA treatment. In the subsequent experiment, OA significantly reduced the biosynthesis of intracellular GSH via the attenuation of $\gamma$-GCS activity. Additionally, there was an obvious reduction in HIF-1 $\alpha$ expression in irradiated cells treated with $\mathrm{OA}$ at different concentrations. In conclusion,
\end{abstract}

Correspondence to: Professor Wensen Jin, Teaching and Research Section of Nuclear Medicine, Anhui Medical University, 81 Mei-Shan Road, Hefei, Anhui 230032, P.R. China

E-mail: wensenjn@139.com

Key words: oleanolic acid, radiosensitivity, glutathione, hypoxia
OA significantly enhanced the radiosensitivity of tumor cells under mimetic hypoxia, through the reduction in intracellular GSH content and HIF-1 $\alpha$ expression.

\section{Introduction}

As known, a hypoxic microenvironment can induce the resistance of cells to radiotherapy in solid tumors (1,2). Several factors are considered to be responsible for the refractory effect of cancer cells to radiation, such as a high level of reduced glutathione (GSH), expression of hypoxia inducible factor-1 (HIF-1), upregulation of the EGFR pathway and the alteration of cell metabolism (3-6). In the development of therapies against tumors, utilizing chemical and natural drugs is a promising method for improving therapeutic response and outcome $(2,7)$.

GSH, the tripeptide thiol L- $\gamma$-glutamyl-L-cysteinylglycine, is the most abundant non-protein thiol in mammalian cells, and is regarded as one of the most important factors for maintaining cellular redox homeostasis and attenuating the injury of oxidative stress. It is synthesized in the cytosol via an enzymatic reaction consisting of two steps: the formation of $\gamma$-glutamylcysteine from L-glutamate and L-cysteine, and the formation of GSH from $\gamma$-glutamylcysteine and glycine. The first step in the enzymatic reaction is catalyzed by $\gamma$-glutamylcystine synthetase ( $\gamma$-GCS), followed by glutathione synthetase (GSS) catalyzing to form GSH. $\gamma$-GCS is also regarded as the key rate-limiting enzyme in de novo GSH synthesis $(8,9)$. Data have been reported indicating that hypoxia may enhance the intracellular GSH content to cause an adaptive response to a hypoxic environment (10-12). Research on the biology of tumors has found that intracellular GSH contents are increased in various types of tumor cells $(13,14)$. Since a high level of GSH often promotes cancer cell survival and resistance to radiotherapy by scavenging reactive oxygen species (ROS) and free radicals (FRs), a GSH-depletion strategy may be used as an effective tool to enhance the radiosensitivity of hypoxic cancer cells $(15,16)$.

HIF-1 is a heterodimer composed of an oxygen-sensitive $\alpha$ subunit and a constitutively expressed $\beta$ subunit. Hydroxylated HIF-1 $\alpha$ forms a complex with the von Hippel-Lindau protein (VHL) resulting in HIF-1 $\alpha$ ubiquitination by the E3 ubiquitin protein ligase and subsequent proteosomal degradation. It 
has been demonstrated that expression of HIF-1 $\alpha$ in tumor cells targets the transcription of many genes involved in DNA repair and cellular resistance to various physical and chemical injuries. High expression of HIF-1 $\alpha$ in tumors indicates ubiquitously poor prognosis and failure of treatment $(17,18)$. The strong relevance of HIF- $1 \alpha$ in the refractory of hypoxic tumor cells to ionizing radiation has been elucidated by numerous experimental data, indicating that the inhibition of HIF- $1 \alpha$ leads to the enhancement of cancer cell radiosensitivity (19-21).

Oleanolic acid (3b-hydroxy-olea-12-en-28-oic acid, OA) extracted from plants belongs to the triterpenoid family. It is commonly used in various diseases, as an anti-inflammatory, for hepatotoxicity protection, and the recovery of the hematopoietic system after irradiation (22-24). In addition, other data have shown that OA and its derivatives potentiated antitumor activity via cell cycle arrest, generating reactive oxygen species (ROS), and loss of mitochondrial membrane potential $(25,26)$. Thereby, OA is considered as a new anticancer drug in combination with other conventional therapeutics (27). Our previous results showed that the monomer OA may increase the lethal effect on aerobic tumor cells exposed to irradiation via the attenuation of intracellular GSH content (28). However, it remains unclear whether OA regulates the radiosensitivity of hypoxic tumor cells. In the present study, cobalt chloride $\left(\mathrm{CoCl}_{2}\right)$ was used to generate a hypoxic microenvironment in lung cancer and glioma cells. Subsequently, the alteration in the radiosensitivity of these hypoxic cells was investigated following OA treatment. Intracellular GSH content and the level of HIF-1 $\alpha$ expression were simultaneously observed under the same conditions.

\section{Materials and methods}

Cell culture and treatment. The rat glioma C6 and human lung cancer A549 cell lines (Cell Bank, Chinese Academy of Sciences) were cultured in RPMI-1640 medium (BAL Gibco, Grand Island, NY, USA) supplemented with $10 \%$ FBS (Gibco), penicillin (100 U/ml), streptomycin $(100 \mu \mathrm{g} /$ $\mathrm{ml}$ ) (Sigma-Aldrich) at $37^{\circ} \mathrm{C}$ in an incubator containing a humid atmosphere of $95 \%$ air and $5 \% \mathrm{CO}_{2}$ and propagated according to the protocol supplied by the American Type Culture Collection. The cells in the exponential phase of growth were incubated in culture media with $100 \mu \mathrm{m} \mathrm{CoCl}_{2}$ (Sigma-Aldrich), a common mimetic hypoxia reagent. OA was purchased from Nanjing Zelang Medical Technology Co., Ltd., (Jiangsu, China) and was dissolved in dimethyl sulfoxide (DMSO; Sigma) at a stock concentration of $250 \mu \mathrm{g} / \mathrm{ml}$ and stored at $-20^{\circ} \mathrm{C}$. The cells were treated with $\mathrm{OA}$ at different concentrations for $24 \mathrm{~h}$ prior to exposure to irradiation.

Cell viability assay. The influence of OA on cell growth was determined using the 3-(4,5-dimethylthiazol-2-yl)-2,5-diphenyltetrazolium bromide (MTT; Sigma) method. C6 and A549 cells were seeded in 96 -well plates at a density of $5 \times 10^{3}$ cells/ well. They were then treated with OA at different concentrations for $24 \mathrm{~h}$. Furthermore, the medium was replaced with fresh medium allowing cells to undergo continuous growth up to $72 \mathrm{~h}$. MTT dye was added to a final concentration of $50 \mathrm{mg} / \mathrm{ml}$, and cells were subsequently incubated for another
$4 \mathrm{~h}$ at $37^{\circ} \mathrm{C}$. The medium containing residual MTT dye was carefully aspirated from each of the wells, and $200 \mu \mathrm{l}$ DMSO (Sigma-Aldrich) was added to each well to dissolve the reduced formazan dye. The fraction of viable cells was calculated by comparing the optical absorbance of the culture exposed to OA treatment with that of the untreated control.

Irradiation. Irradiation was emitted using a $6 \mathrm{MV}$ X-ray linear accelerator (Varian Medical Systems, Inc., Palo Alto, CA, USA) at a dose rate of $250 \mathrm{cGy} / \mathrm{min}$.

Clonogenic assay. The radiosensitivity of tumor cells was determined using the clonogenic assay. Both tumor cell lines were seeded and cultured overnight at an appropriate density in T25 flasks, and subsequently the drugs at different concentrations were added into the medium for $24 \mathrm{~h}$. After being pretreated with control and OA, cells were subjected to $0,1,2$, 3, 5 or 7 Gy X-ray irradiation. The medium was then replaced with fresh medium allowing cells to continuously grow for colony formation for 9 to 12 days. Cell colonies were fixed by absolute methanol and stained with Giemsa (Sigma-Aldrich) for counting. The clonogenic survival fraction (SF) was calculated as the number of colonies/(the number of seeded cells $\mathrm{x}$ plating efficiency). Plating efficiency was defined as the number of colonies/the number of seeded cells of the untreated control. Survival curve was fitted with the single target multi-model of an equation: $S=1-1\left(1-\mathrm{e}^{-\mathrm{D}^{/} \mathrm{D}_{0}}\right)^{\mathrm{N}}$. The oxygen enhancement ratio (OER) was calculated accordingly, comparing the hypoxic $\mathrm{D}_{0}$ with the corresponding aerobic $\mathrm{D}_{0}$.

Micronucleus assay. Micronucleus (MN) frequencies were tested with the cytokinesis-block technique as a biological end point for the response of cells under mimetic hypoxia to irradiation. Briefly, the cells were exposed to $0.83 \mu \mathrm{g} / \mathrm{ml}$ cytochalasin B (Sigma-Aldrich) for 19-20 h followed by $75 \mathrm{mM}$ $\mathrm{KCl}$ hypotonic treatment for 1-3 min and then fixed in situ with methanol:acetic acid (9:1 v/v) for $30 \mathrm{~min}$. Air-dried cells were stained with $5 \%$ Giemsa for $10 \mathrm{~min}$. Micronuclei were scored in binucleated cells, and the formation of binucleated cells was measured as the percentage of the total number of cells scored. For each sample, at least 1,000 binucleated cells were counted. The MN yield, $\mathrm{Y}_{\mathrm{MN}}$, is the ratio of the number of micronuclei to the number of binucleated cells scored.

Intracellular GSH assay. After triplicate samples of $10^{6}$ cells were treated with different reagents, the intracellular GSH content was measured with the glutathione reductase/5,5'dithiobis-(2-nitrobenzoic acid) (DTNB) recycling assay kit (Beyotime Institute of Biotechnology, Shanghai, China) following the methods recommended by the manufacturer. Briefly, GSH was determined using a reaction mixture, containing $50 \mu \mathrm{l}$ of cell lysates, $50 \mu \mathrm{l}$ of $2.4 \mathrm{mM}$ DTNB, and $50 \mu \mathrm{l}$ of $10.64 \mathrm{mU} / \mu \mathrm{l}$ glutathione reductase in the assay buffer (pH 7.5) containing $153 \mathrm{mM}$ sodium phosphate and $8.4 \mathrm{mM}$ EDTA. After a 5 -min incubation at $25^{\circ} \mathrm{C}$, the reaction was started by the addition of $50 \mu \mathrm{l}$ NADPH solution $(0.16 \mathrm{mg} /$ $\mathrm{ml}$ ) in assay buffer. The standard sample and checking sample cuvettes were placed into a dual-beam spectrophotometer, and the increases in absorbance at $412 \mathrm{~nm}$ were followed as a function of time. 
Intracellular $\gamma$-GCS activity assay. Cells $\left(10^{6}\right)$ were homogenized in $50 \mathrm{mM}$ potassium phosphate $(\mathrm{pH} 7.5)$ containing TES/SB buffer (20 mM Tris, $1 \mathrm{mM}$ EDTA, $250 \mathrm{mM}$ sucrose, $20 \mathrm{mM}$ sodium borate, $2 \mathrm{mM}$ serine) for the $\gamma$-GCS assay. Homogenates were centrifuged at $12,000 \mathrm{rpm}\left(15 \mathrm{~min}, 4^{\circ} \mathrm{C}\right)$, and the supernatants were maintained on ice for determination of enzyme activity. The protein concentration of the cell supernatants was measured using the Bio-Rad DC protein assay kit (Bio-Rad Laboratories, Hertfordshire UK) and enzyme activity was reported as units $/ \mathrm{mg}$ protein, where a unit of activity is the amount of enzyme required to convert $1 \mu$ mole of substrate to product per minute at $25^{\circ} \mathrm{C}$. The $\gamma$-GCS assay is an adaptation of the method previously described, in which $\gamma$-GCS in cell extracts synthesizes $\gamma$-glutamylcysteine which is then reacted with 2,3-naphthalenedicarboxaldehyde (NDA) to form a highly fluorescent product that can be measured fluorimetrically at $520 \mathrm{~nm}(29)$.

Intracellular GSS activity assay. Tumor cells were plated in $60-\mathrm{mm}$ culture dishes at a density of $10^{6}$ cells/dish then divided into different groups for various methods of pretreatment. The intracellular GSS content was measured using the GSS assay kit (Hefei Lanxu Biotech Co., Ltd., Hefei, China). Briefly, the cells were subjected to repeated freeze-thaw cycles to lyse these cells for release of intracellular components. Cell lysates were centrifuged at $3,000 \mathrm{rpm}\left(20 \mathrm{~min}, 4^{\circ} \mathrm{C}\right)$, and the supernatants were maintained on ice for determination of enzyme activity. All procedures were performed according to the protocol of the kit. After the reaction was terminated, the absorbance was measured at $450 \mathrm{~nm}$ on an ELISA reader. The activity of GSS in the sample was then determined by comparing the OD of the samples to the standard curve.

Western blot analysis of HIF-1 $\alpha$ expression. The cells in the different treatment groups were scraped off from the culture flasks and lysed in lysis buffer containing $10 \%$ glycerol, $10 \mathrm{mM}$ Tris-HCl (pH 6.8), 1\% SDS, $5 \mathrm{mM}$ dithiothreitol (DTT) and $1 \mathrm{X}$ complete protease inhibitor cocktail (Sigma, St. Louis, MO, USA). The method of Bradford was used to detect the concentrations of protein in the diverse samples. The protein concentration was measured using an auto multifunction microplate reader. Fifty micrograms of proteins was separated by $8 \%$ polyacrylamide-SDS in consecutive gel electrophoresis. The separated proteins were electrophoretically transferred to a polyvinylidene difluoride membrane. Membranes were blocked with 5\% skim milk in Tris-buffered saline (TBS) containing $0.1 \%$ Tween-20 at room temperature for $1 \mathrm{~h}$ and then incubated with mouse HIF-1 $\alpha$ antibody (Abcam, Cambridge, MA, USA) at a 1:500 dilution overnight at $4^{\circ} \mathrm{C}$, followed by goat anti-mouse $\mathrm{IgG}$ for $1 \mathrm{~h}$ at room temperature. Signals were detected with enhanced chemiluminescence (ECL Plus; Amersham, Pittsburgh, PA, USA). Microtubule protein (Tubulin; Abcam) at a 1:1,000 dilution was used as an internal control to observe the changes in the HIF-1 $\alpha$ bands.

Statistical analysis. Data are reported as the means \pm SEM of three separate experiments. Statistical significance was measured by the independent sample t-test and analysis of variance. A value of $\mathrm{P}<0.05$ was considered to indicate a statistically significant result.
A

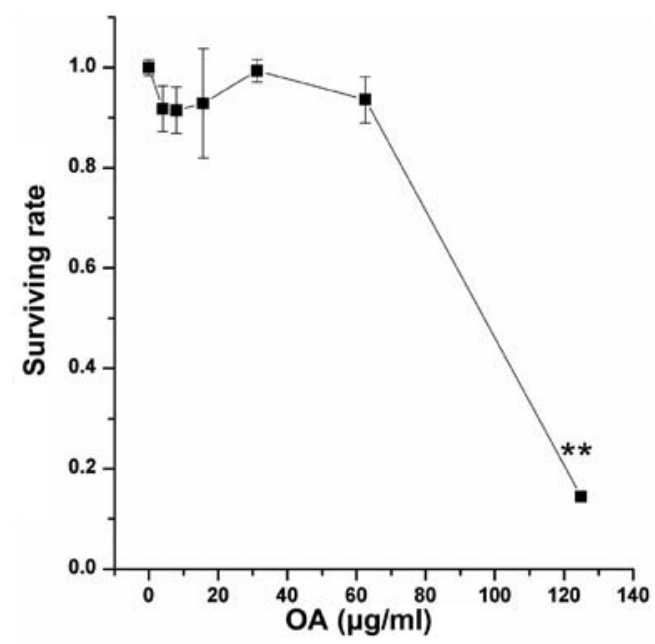

B

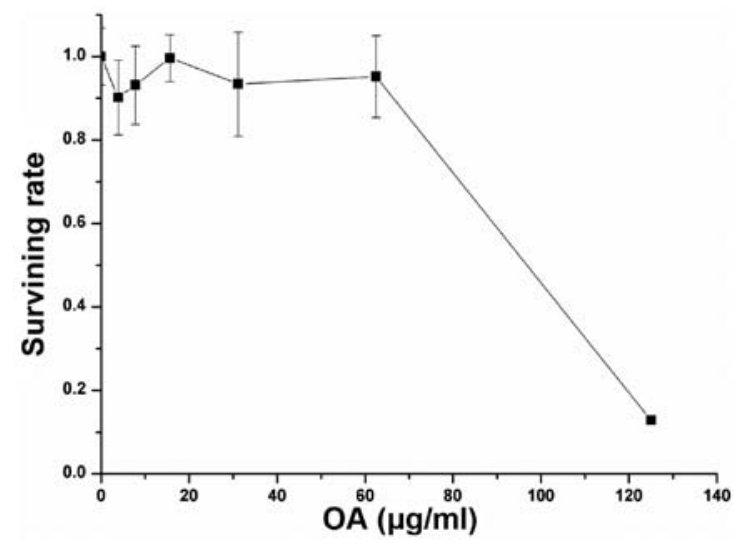

Figure 1. Cytotoxic effect of OA on hypoxic C6 and A549 cells. Inhibition of survival by OA in the hypoxic (A) C6 and (B) A549 cells. ${ }^{* *} \mathrm{P}<0.01$, compared with the control.

\section{Results}

Selection of the experimental concentration of OA. The cytotoxicity test showed that the half maximal inhibitory concentrations $\left(\mathrm{IC}_{50}\right)$ of $\mathrm{OA}$ in the hypoxic $\mathrm{C} 6$ and $\mathrm{A} 549$ cells were 80 and $81 \mu \mathrm{g} / \mathrm{ml}$, respectively (Fig. 1). The concentrations of OA at $16 \mu \mathrm{g} / \mathrm{ml}\left(20 \% \mathrm{IC}_{50}\right)$ and $24 \mu \mathrm{g} / \mathrm{ml}\left(30 \% \mathrm{IC}_{50}\right)$ were used to pretreat the cells in order to observe the alteration of radiosensitivity in both hypoxic tumor cell lines.

Alteration of tumor cell radiosensitivity. No statistical differences were observed in the numbers of colonies formed in the C6 and A549 cells with $\mathrm{CoCl}_{2}$ treatment and those without $\mathrm{CoCl}_{2}$ treatment. However, after the cells were exposed to radiation, both cell lines in the mimetic hypoxic microenvironment had a higher resistance to irradiation. The OER values of the C6 and A549 cells were 1.52 and 1.31, respectively (Fig. 2A and B). Subsequently, we observed the alteration in radiosensitivity of the C6 and A549 cells following treatment with OA at the different concentrations. After the hypoxic cells were exposed to irradiation, the SF of the cells treated with OA was lower than that of the cells without OA treatment. Following calculation of the sensitive enhancement ratio (SER), the SER of the irradiated cells was elevated concomitant with the increase in OA concentrations. The SERs of the hypoxic C6 

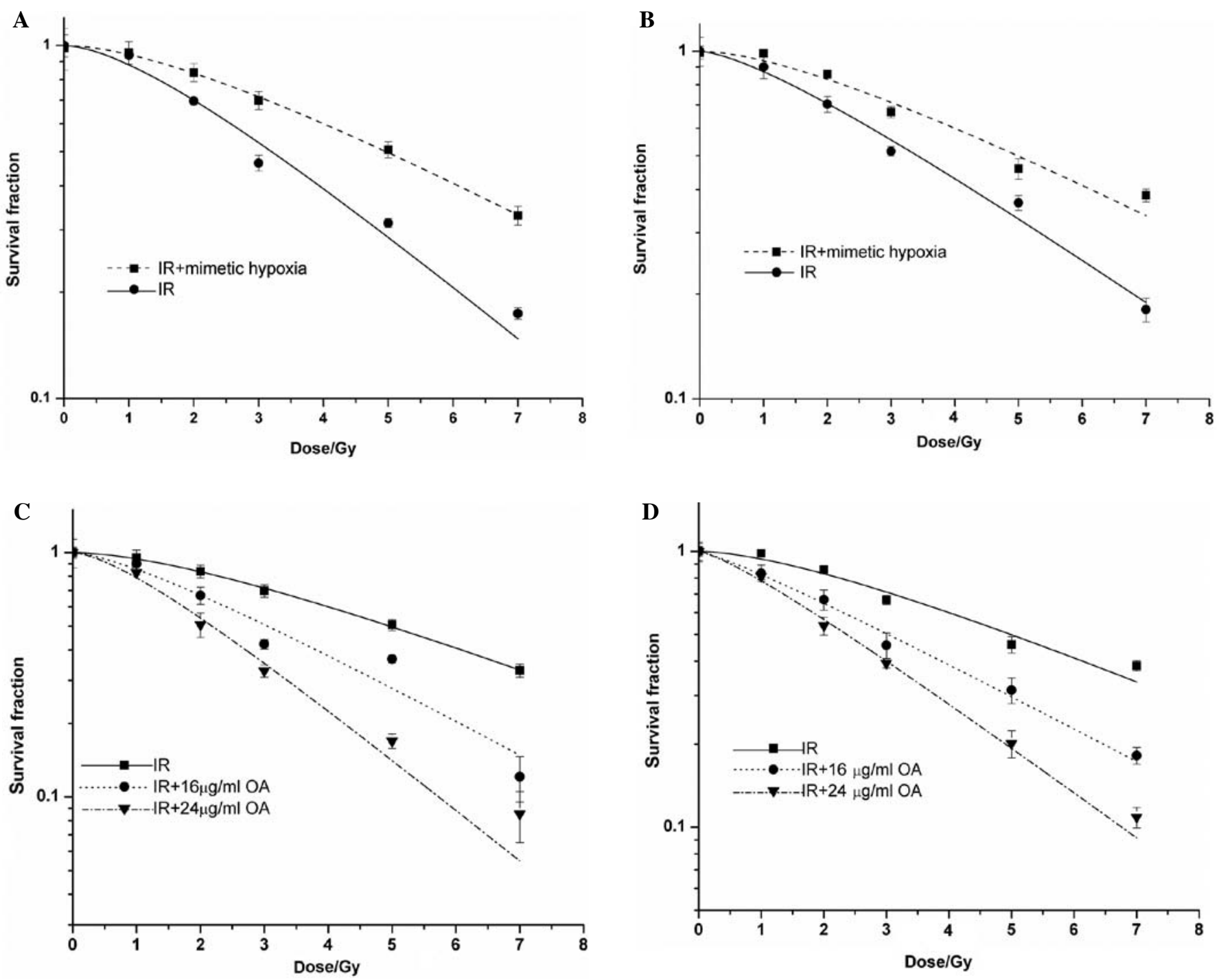

Figure 2. Alteration in the radiosensitivity of hypoxic C6 and A549 cells pretreated with OA. (A and B) The radiosensitivity of hypoxic C6 and A549 cells, respectively. (C) Clonogenic cell survival curves were obtained from mimetic hypoxic C6 cells pretreated with OA at different concentrations for $24 \mathrm{~h}$ and then exposed to 1-7 Gy irradiation (IR). The SERs of $20 \% \mathrm{IC}_{50}$ and $30 \% \mathrm{IC}_{50}$ concentrations of OA were 1.42 and 2.09, respectively. (D) Cell survival curves were obtained from A549 cells pretreated similarly to C6 cells. The SERs of $10 \% \mathrm{IC}_{50}, 20 \% \mathrm{IC}_{50}$ and $30 \% \mathrm{IC}_{50}$ concentrations of OA were 1.25 and 1.71 , respectively.

A

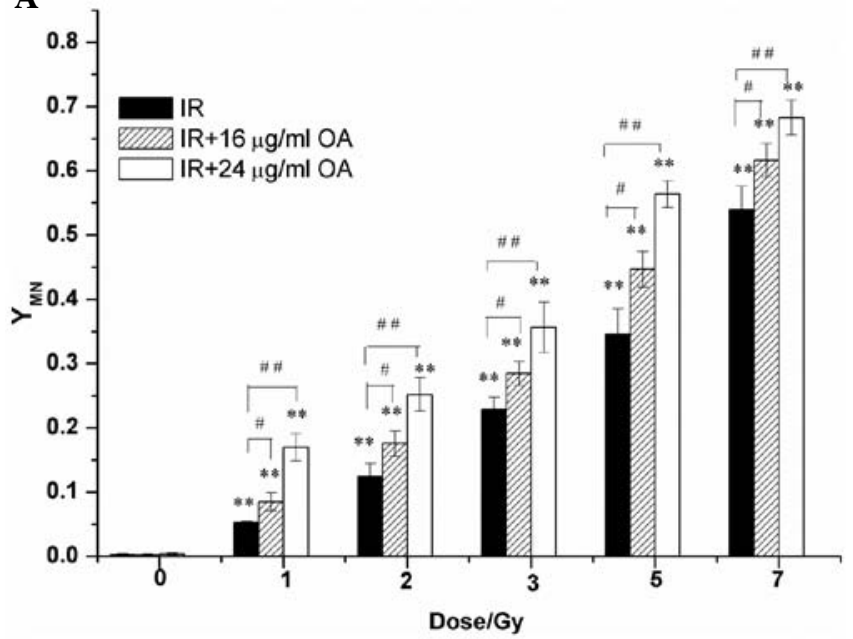

B

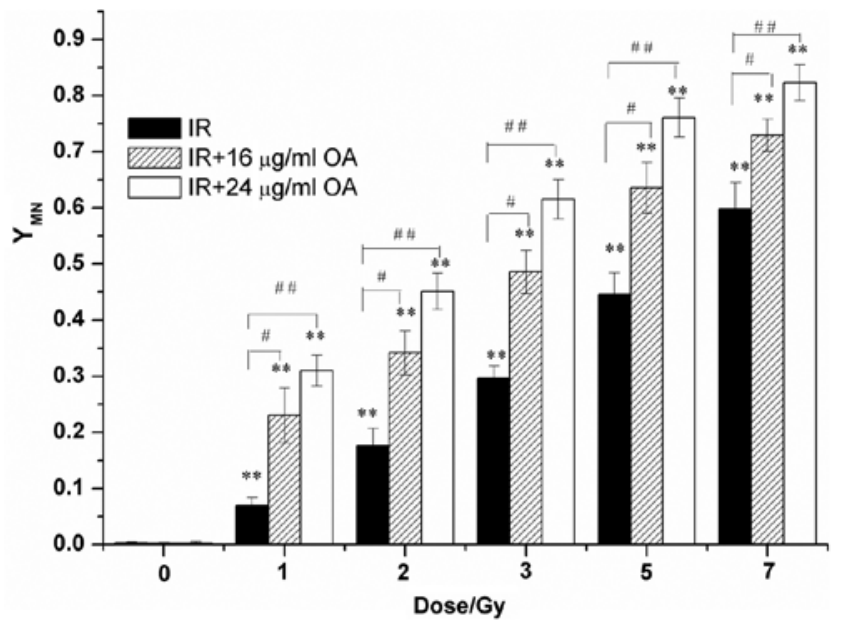

Figure 3. Alterations in the micronucleus rate of hypoxic tumor cells exposed to irradiation following OA pretreatment. MN generation in (A) C6 and (B) A549 cells irradiated (IR) with different doses of $\mathrm{X}$-rays prior to $\mathrm{OA}$ treatment. The data are from three independent experiments. ${ }^{* *} \mathrm{P}<0.01$, compared to the $\mathrm{Y}_{\mathrm{MN}}$ of the same cell line without OA treatment and irradiation. ${ }^{\#} \mathrm{P}<0.05$ and ${ }^{\# \#} \mathrm{P}<0.01$, compared to the $\mathrm{Y}_{\mathrm{MN}}$ of the same irradiated cell line without $\mathrm{OA}$ treatment. 
A

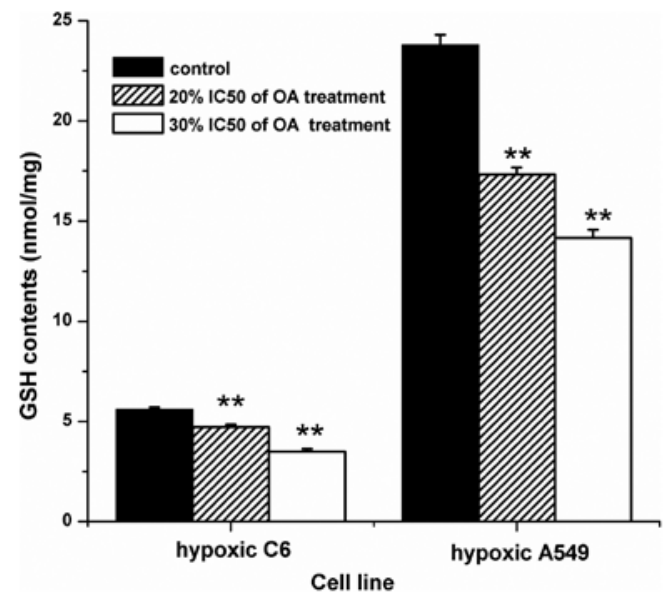

B

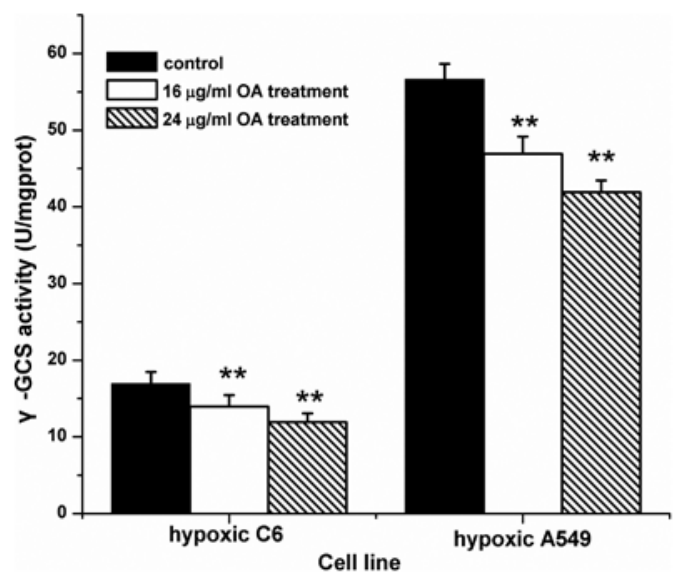

C

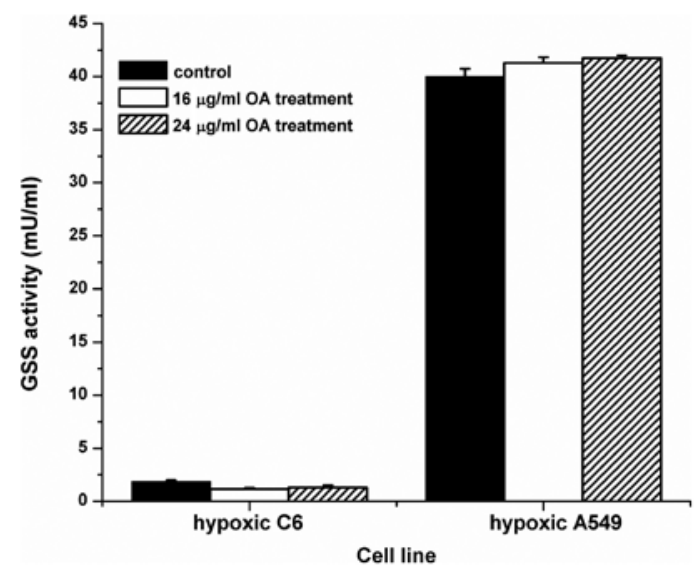

Figure 4. Influence of OA on the synthesis of intracellular GSH. Data are from 3 independent experiments. Influence of OA on the (A) level of GSH, (B) activity of $\gamma$-GCS and (C) activity of GSS. ${ }^{* *} \mathrm{P}<0.01$, compared to the cells in the absence of OA treatment.

and $\mathrm{A} 549$ cells treated with $\mathrm{OA}$ at $30 \% \mathrm{IC}_{50}$ were 2.09 and 1.71, respectively (Fig. 2C and D).

Changes in the intracellular micronucleus frequencies. MN assay showed that there was no obvious influence of OA on the frequencies of $\mathrm{MN}$ in both hypoxic cell lines unexposed to irradiation. Subsequently, the numbers of intracellular MN were significantly increased concomitant with the irradiation doses. When both irradiated cell lines were pretreated with $\mathrm{OA}$ at different concentrations, further enhancement in the numbers of intracellular MN was noted. Compared with the irradiated cells without OA treatment, the irradiated cells pretreated with 16 and $24 \mu \mathrm{g} / \mathrm{ml} \mathrm{OA}$ displayed a statistically significant increase in intracellular MN frequencies (Fig. 3).

Influence of OA on GSH level, the activity of $\gamma$-GCS and GSS. To further observe the mechanism of the influence of $\mathrm{OA}$ on the radiosensitivity of hypoxic cells, intracellular GSH levels were measured following treatment of OA at different concentrations for $24 \mathrm{~h}$. Significant decreases in the GSH levels of hypoxic $\mathrm{C} 6$ cells were noted in the presence of OA, when compared with levels in the absence of OA. Moreover, a similar phenomenon occurred in hypoxic A549 cells, when intracellular GSH levels showed a gradually declining tendency concomitant with increases in OA concentrations (Fig. 4A). Since $\gamma$-GCS is the key limiting-enzyme in the synthesis of intracellular GSH, its activity was further measured. As shown in Fig. 4B, the different concentrations of OA significantly decreased $\gamma$-GCS activity in both hypoxic cell lines. Notably, the activity of GSS, another synthetic enzyme, did not exhibit a statistically significant change in the tumor cells with the same treatments (Fig. 4C).

Change in the intracellular HIF-1 $\alpha$ level by OA pretreatment. High expression of intracellular HIF-1 $\alpha$ was induced by $\mathrm{CoCl}_{2}$ treatment. The hypoxic cells exposed to irradiation still exhibited high levels of HIF-1 $\alpha$. Meanwhile, HIF-1 $\alpha$ expression in the hypoxic cells without irradiation did not exhibit a statistically significant change following OA treatment. However, the combination of OA treatment with irradiation suppressed the high levels of HIF-1 $\alpha$ expression in the hypoxic cells (Fig. 5).

\section{Discussion}

Tumor hypoxia, which is generally attributed to an imbalance between the demand and supply of oxygen and poorly organized vasculature, is observed in many tumor types particularly glioma and lung cancer (30). Hypoxia appears to be the most important factor in the development of radioresistance, invasiveness and more aggressive tumor phenotypes $(17,31)$. Therefore, regarding glioma and lung cancer, enhancement of the efficacy of radiotherapy by hypoxic radiosensitizers is favorable for the improvement of the radiotherapeutic effectiveness in these two invariably fatal diseases. Numerous natural compounds from the extracts of plants such as curcumin and soy isoflavones have been developed and screened $(32,33)$. In a previous study, we found that OA enhanced the radiosensitizing effect on aerobic C6 and A549 cells (28). Subsequently, the effect of OA on the radiosensitivity of tumor cells with mimetic hypoxia treatment was observed in the present study.

Based on a large number of experimental data, preliminary exposure to mimetic hypoxia with $\mathrm{CoCl}_{2}$ inducing a similar to real hypoxic condition may increase the tolerance against subsequent injury of other biological and physicochemical factors including chemotherapeutic drugs, ionizing radiation and tert-butyl-hydroperoxide-induced oxidative stress (34-36). Therefore, $\mathrm{CoCl}_{2}$ can be universally used as a chemical reagent that induces biochemical and molecular responses similar to those observed under a hypoxic condition $(37,38)$. Our previous results also showed that similar to hypoxia, $\mathrm{CoCl}_{2}$ 
A

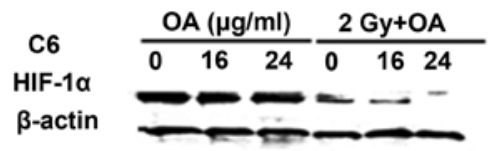

B

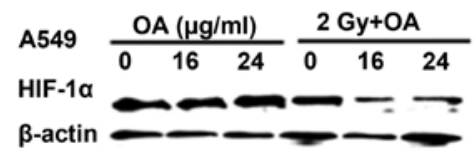

C

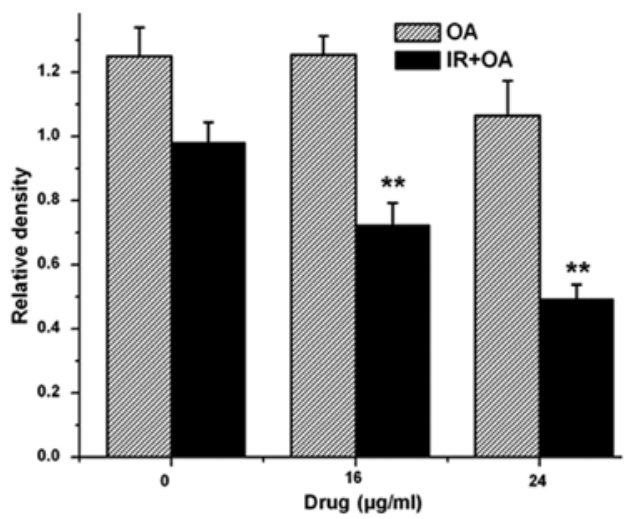

D

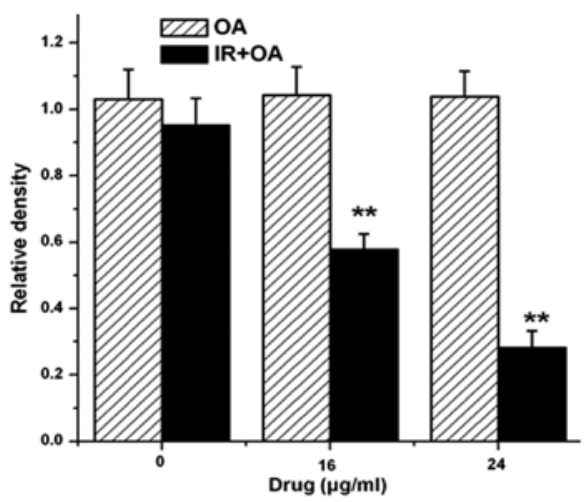

Figure 5. Inhibition of HIF-1 $\alpha$ levels by OA in hypoxic cells. (A and B) Representative gel images from three separate western blot experiments. (A and C) The change in HIF-1 $\alpha$ expression in hypoxic C6 cells. (B and D) The change in HIF-1 $\alpha$ expression in hypoxic A549 cells. ${ }^{* *} \mathrm{P}<0.01$, compared to the control.

enhanced cellular radioresistance and increased the levels of HIF-1 $\alpha$ (36). We selected two different concentrations of $\mathrm{OA}$, with no obvious influence on cell viability, to carry out the present experiment. It was further observed that different doses of radiation combined with OA significant inhibited the cell growth and an additive lethal effect was noted. According to the calculation of $\mathrm{D}_{0}$ and SERs, the sensitivity of tumor cells to radiation was significantly enhanced by $\mathrm{OA}$ treatment.

The protective effect of GSH is very important for the resistance of cancer cells against radiotherapeutics (15). We, therefore, investigated the influence of OA on the level of GSH and the capability of regulatory enzymes in hypoxic cells. The results of the present study clearly showed that the levels of GSH in the two hypoxic cell lines were downregulated following pretreatment of $\mathrm{OA}$ at 20 and $30 \% \mathrm{IC}_{50}$. Regarding the biosynthesis of GSH, the inhibition of $\gamma$-GCS activity was subsequently observed in the hypoxic cells in the presence of OA. However, the phenomenon, the alteration of GSS activity, was not found under the same treatment condition. It was demonstrated that OA might decrease the level of GSH via the inhibition of $\gamma$-GCS activity in hypoxic tumor cells. According to our previous study and other data, there was a higher level of cellular GSH in hypoxic cells or mimetic hypoxic cells compared with that in aerobic cells, resulting in the refractoriness of cells to irradiation $(36,39,40)$. Therefore, the combination of OA and radiation to effectively destroy hypoxic tumor cells is strongly correlated with the inhibition of intracellular GSH biosynthesis.

As one of the biomarkers, MN assay is usually used in the observation of DNA damage by radiation leading to the formation of single and double strand breaks. The MN frequency in binucleated cells indicates the degree of radiation damage (41-43). Data have demonstrated that increased GSH participates non-enzymatically in the protection against DNA damage by irradiation following the significant reduction in MN frequency $(44,45)$. On the contrary, the attenuation of GSH increased the formation of MN in irradiated cells (46). Our results showed that, compared to the irradiated cells without OA treatment, there was a statistical elevation in the $\mathrm{MN}$ frequency in the hypoxic cells treated with OA at different concentrations after irradiation. It was further found that OA increased the radiosensitivity of hypoxic cells by the depletion of intracellular GSH.

HIF-1 $\alpha$ has attracted attention in the field of cancer radiochemotherapy. The expression of HIF-1 $\alpha$ induced by hypoxia or $\mathrm{CoCl}_{2}$ imitating hypoxia enhances the refractoriness of cells to irradiation $(47,48)$. On the other hand, increased radiosensitivity of hypoxic cells is associated with the inhibition of intracellular HIF-1 $\alpha$ (4). The results from our experiment were not due to the statistical alteration of HIF-1 $\alpha$ expression by OA or radiation treatment alone. Notably, the findings showed that, after the hypoxic cells were exposed to irradiation, there were significantly decreased levels of HIF-1 $\alpha$ following pretreatment of OA at 20 and $30 \% \mathrm{IC}_{50}$. Since HIF-1 $\alpha$ is involved in the restoration of DNA damage in irradiated cells, OA effectively attenuated the repair potential in both hypoxic cell lines following irradiation by inhibition of HIF-1 $\alpha$ expression. Other data indicate that the inhibition of intracellular HIF-1 $\alpha$ by natural products extracted from plants such as soy isoflavones and honokiol reduced the resistance of hypoxic tumor cells to irradiation $(33,49)$. In addition, research revealed that three triterpenic acids extracted from natural products, including oleanolic acid, ursolic acid and maslinic acid, suppressed the expression of HIF-1 $\alpha$ in human liver cancer cells exposed to a hypoxic microenvironment as observed in a previous study similarly to our observation (50). Therefore, the downregulation of HIF-1 $\alpha$ level is another target, by which OA modulated the sensitivity of the two hypoxic tumor cell lines to radiation.

In conclusion, the present study demonstrated that, under chemical hypoxia, OA increased the sensitivity of rat glioma C6 cells and human lung cancer A549 cells to radiation. The primary mechanism of the effect of OA may involve the downregulation of intracellular GSH synthesis by inhibiting the activity of $\gamma$-GCS and the decreased expression of HIF- $1 \alpha$ after irradiation. Collectively, the present findings and our previous report suggest that OA has the potential to improve the radiation response for tumor treatment. 


\section{Acknowledgements}

The present study was financially supported by the Anhui Provincial Natural Science Foundation, China (grant no. 11040606M210).

\section{References}

1. Toustrup K, Sørensen BS, Alsner J and Overgaard J: Hypoxia gene expression signatures as prognostic and predictive markers in head and neck radiotherapy. Semin Radiat Oncol 22: 119-127, 2012.

2. Bischoff P, Altmeyer A and Dumont F: Radiosensitising agents for the radiotherapy of cancer: advances in traditional and hypoxia targeted radiosensitisers. Expert Opin Ther Pat 19: 643-662, 2009

3. Tian J, Peehl DM, Zheng W and Knox SJ: Anti-tumor and radiosensitization activities of the iron chelator HDp44mT are mediated by effects on intracellular redox status. Cancer Lett 298: 231-237, 2010.

4. Meijer TW, Kaanders JH, Span PN and Bussink J: Targeting hypoxia, HIF-1, and tumor glucose metabolism to improve radiotherapy efficacy. Clin Cancer Res 18: 5585-5594, 2012.

5. Karar J and Maity A: Modulating the tumor microenvironment to increase radiation responsiveness. Cancer Biol Ther 8 1994-2001, 2009.

6. Min JW, Kim KI, Kim HA, et al: INPP4B-mediated tumor resistance is associated with modulation of glucose metabolism via hexokinase 2 regulation in laryngeal cancer cells. Biochem Biophys Res Commun 440: 137-142, 2013.

7. Raffoul JJ, Banerjee S, Che M, et al: Soy isoflavones enhance radiotherapy in a metastatic prostate cancer model. Int J Cancer 120: 2491-2498, 2007.

8. Forman HJ, Zhang H and Rinna A: Glutathione: overview of its protective roles, measurement, and biosynthesis. Mol Aspects Med 30: 1-12, 2009.

9. Botta D, White CC, Vliet-Gregg P, et al: Modulating GSH synthesis using glutamate cysteine ligase transgenic and genetargeted mice. Drug Metab Rev 40: 465-477, 2008.

10. Catalano V, Turdo A, Di Franco S, Dieli F, Todaro M and Stassi G: Tumor and its microenvironment: a synergistic interplay. Semin Cancer Biol 23: 522-532, 2013.

11. Saxena S, Shukla D, Saxena S, et al: Hypoxia preconditioning by cobalt chloride enhances endurance performance and protects skeletal muscles from exercise-induced oxidative damage in rats. Acta Physiol 200: 249-263, 2010.

12. Oh C, Dong Y, Harman C, Mighty HE, Kopelman J and Thompson LP: Chronic hypoxia differentially increases glutathione content and $\gamma$-glutamyl cysteine synthetase expression in fetal guinea pig organs. Early Hum Dev 84: 121-127, 2008.

13. Ruiz-Gómez MJ, Souviron A, Martínez-Morillo M and Gil L: P-glycoprotein, glutathione and glutathione S-transferase increase in a colon carcinoma cell line by colchicine. J Physiol Biochem 56: 307-312, 2000.

14. Honda T, Coppola S, Ghibelli L et al: GSH depletion enhances adenoviral bax-induced apoptosis in lung cancer cells. Cancer Gene Ther 11: 249-255, 2004.

15. Simons AL, Parsons AD, Foster KA, Orcutt KP, Fath MA and Spitz DR: Inhibition of glutathione and thioredoxin metabolism enhances sensitivity to perifosine in head and neck cancer cells. J Oncol 2009: 519563, 2009.

16. Boivin A, Hanot M, Malesys C, Maalouf M, Rousson R, Rodriguez-Lafrasse C and Ardail D: Transient alteration of cellular redox buffering before irradiation triggers apoptosis in head and neck carcinoma stem and non-stem cells. PLoS One 6 : e14558, 2011

17. Yang Y, Sun M, Wang L and Jiao B: HIFs, angiogenesis, and cancer. J Cell Biochem 114: 967-974, 2013.

18. Semenza GL: Hypoxia-inducible factors: mediators of cancer progression and targets for cancer therapy. Trends Pharmacol Sci 33: 207-214, 2012

19. Pires IM, Olcina MM, Anbalagan S, et al: Targeting radiationresistant hypoxic tumour cells through ATR inhibition. Br J Cancer 107: 291-299, 2012.

20. Lu H, Liang K, Lu Y and Fan Z: The anti-EGFR antibody cetuximab sensitizes human head and neck squamous cell carcinoma cells to radiation in part through inhibiting radiationinduced upregulation of HIF-1 $\alpha$. Cancer Lett 322: 78-85, 2012.
21. Staab A, Fleischer M, Loeffler J, et al: Small interfering RNA targeting HIF-1 $\alpha$ reduces hypoxia-dependent transcription and radiosensitizes hypoxic HT 1080 human fibrosarcoma cells in vitro. Strahlenther Onkol 187: 252-259, 2011.

22. Reisman SA, Aleksunes LM and Klaassen CD: Oleanolic acid activates Nrf2 and protects from acetaminophen hepatotoxicity via Nrf2-dependent and Nrf2-independent processes. Biochem Pharmacol 77: 1273-1282, 2009.

23. Hsu HY, Yang JJ and Lin CC: Effects of oleanolic acid and ursolic acid on inhibiting tumor growth and enhancing the recovery of hematopoietic system postirradiation in mice. Cancer Lett 111: 7-13, 1997.

24. Yang EJ, Lee W, Ku SK, Song KS and Bae JS: Anti-inflammatory activities of oleanolic acid on HMGB1 activated HUVECs. Food Chem Toxicol 50: 1288-1294, 2012.

25. Fujiwara Y, Komohara Y, Kudo R, Tsurushima K, Ohnishi K, Ikeda $\mathrm{T}$ and Takeya M: Oleanolic acid inhibits macrophage differentiation into the M2 phenotype and glioblastoma cell proliferation by suppressing the activation of STAT3. Oncol Rep 26: $1533-1537,2011$.

26. Chakravarti B, Maurya R, Siddiqui JA, Bid HK, Rajendran SM, Yadav PP and Konwar R: In vitro anti-breast cancer activity of ethanolic extract of Wrightia tomentosa: role of pro-apoptotic effects of oleanolic acid and urosolic acid. J Ethnopharmacol 142: 72-79, 2012

27. Yamai H, Sawada N, Yoshida T, et al: Triterpenes augment the inhibitory effects of anticancer drugs on growth of human esophageal carcinoma cells in vitro and suppress experimental metastasis in vivo. Int J Cancer 125: 952-960, 2009.

28. Wang J, Yu M, Xiao L, Xu S, Yi Q and Jin W: Radiosensitizing effect of oleanolic acid on tumor cells through the inhibition of GSH synthesis in vitro. Oncol Rep 30: 917-924, 2013.

29. White CC, Viernes H, Krejsa CM, Botta D and Kavanagh TJ: Fluorescence-based microtiter plate assay for glutamate-cysteine ligase activity. Anal Biochem 318: 175-180, 2003.

30. Lee ST and Scott AM: Hypoxia positron emission tomography imaging with ${ }^{18}$ f-fluoromisonidazole. Semin Nucl Med 37: 451-461, 2007.

31. Bulnes S, Bengoetxea H, Ortuzar N, Argandoña EG, GarciaBlanco A, Rico-Barrio I and Lafuente JV: Angiogenic signalling pathways altered in gliomas: selection mechanisms for more aggressive neoplastic subpopulations with invasive phenotype. J Signal Transduct 2012: 597915, 2012.

32. Aravindan S, Natarajan M, Herman TS, Awasthi V and Aravindan N: Molecular basis of 'hypoxic' breast cancer cell radio-sensitization: phytochemicals converge on radiation induced Rel signaling. Radiat Oncol 8: 46, 2013.

33. Singh-Gupta V, Zhang H, Banerjee S, Kong D, Raffoul JJ, Sarkar FH and Hillman GG: Radiation-induced HIF-1 $\alpha$ cell survival pathway is inhibited by soy isoflavones in prostate cancer cells. Int J Cancer 124: 1675-1684, 2009.

34. Ji Z, Yang G, Shahzidi S, Tkacz-Stachowska K, Suo Z, Nesland JM and Peng Q: Induction of hypoxia-inducible factor-1 $\alpha$ overexpression by cobalt chloride enhances cellular resistance to photodynamic therapy. Cancer Lett 244: 182-189, 2006.

35. Piret JP, Lecocq C, Toffoli S, Ninane N, Raes M and Michiels C: Hypoxia and $\mathrm{CoCl}_{2}$ protect HepG2 cells against serum deprivation- and t-BHP-induced apoptosis: a possible anti-apoptotic role for HIF-1. Exp Cell Res 295: 340-349, 2004.

36. Jin W, Wang J, Xu S, Xiao L, Chen G, Zhang W and Li J: Radioprotective effect on HepG2 cells of low concentrations of cobalt chloride: induction of hypoxia-inducible factor-1 alpha and clearance of reactive oxygen species. J Radiat Res 54: 203-209, 2013.

37. Law PC, Auyeung KK, Chan LY and Ko JK: Astragalus saponins downregulate vascular endothelial growth factor under cobalt chloride-stimulated hypoxia in colon cancer cells. BMC Complement Altern Med 12: 160, 2012.

38. Brusevold IJ, Husvik C, Schreurs O, Schenck K, Bryne M and Søland TM: Induction of invasion in an organotypic oral cancer model by $\mathrm{CoCl}_{2}$, a hypoxia mimetic. Eur J Oral Sci 118: 168-176, 2010.

39. Donnelly ET, Liu Y, Paul TK and Rockwell S: Effects of motexafin gadolinium on DNA damage and X-ray-induced DNA damage repair, as assessed by the Comet assay. Int $\mathbf{J}$ Radiat Oncol Biol Phys 62: 1176-1186, 2005.

40. Vukovic V, Nicklee T and Hedley DW: Differential effects of buthionine sulphoximine in hypoxic and non-hypoxic regions of human cervical carcinoma xenografts. Radiother Oncol 60: 69-73, 2001. 
41. Kashino G, Prise KM, Suzuki K, et al: Effective suppression of bystander effects by DMSO treatment of irradiated CHO cells. J Radiat Res 48: 327-333, 2007.

42. Thierens $\mathrm{H}$ and Vral A: The micronucleus assay in radiation accidents. Ann Ist Super Sanita 45: 260-264, 2009.

43. Romm H, Barnard S, Boulay-Greene H, et al: Laboratory intercomparison of the cytokinesis-block micronucleus assay. Radiat Res 180: 120-128, 2013

44. Tokuzumi S, Hori M, Monobe M, Hosoi Y and Kojima S: Effect of nitric oxide on $\gamma$-ray-induced micronucleus frequency in RAW264.7 cells. Radiat Res 164: 723-732, 2005.

45. Kumar M, Meena P, Verma S, Kumar M and Kumar A: Antitumour, anti-mutagenic and chemomodulatory potential of Chlorophytum borivilianum. Asian Pac J Cancer Prev 11: 327-334, 2010.

46. Hanot M, Boivin A, Malésys C, et al: Glutathione depletion and carbon ion radiation potentiate clustered DNA lesions, cell death and prevent chromosomal changes in cancer cells progeny. PLoS One 7: e44367, 2012.
47. Sendoel A, Kohler I, Fellmann C, Lowe SW and Hengartner MO: HIF-1 antagonizes p53-mediated apoptosis through a secreted neuronal tyrosinase. Nature 465: 577-583, 2010.

48. Indovina P, Ferrante A, Rainaldi G and Santini MT: Hypoxia and ionizing radiation: changes in adhesive properties and cell adhesion molecule expression in MG-63 three-dimensional tumor spheroids. Cell Commun Adhes 13: 185-198, 2006.

49. Lan KL, Lan KH, Sheu ML, et al: Honokiol inhibits hypoxiainducible factor-1 pathway. Int J Radiat Biol 187: 579-590, 2011.

50. Lin CC, Huang CY, Mong MC, Chan CY and Yin MC: Antiangiogenic potential of three triterpenic acids in human liver cancer cells. J Agric Food Chem 59: 755-762, 2011. 